\title{
ЭкСпертизд
}

ЮРЕВИЧ Максим Андреевич - научный сотрудник иентра макроэкономических исследований Финансового университета при Правительстве РФ (125993, Россия, г. Москва, Ленинградский пр-кт, 49, mayurevich@fa.ru)

ЕКИМОВА Наталья Александровна - кандидат экономических наук, доцент; ведущий научный сотрудник иентра макроэкономических исследований Финансового университета при Правительстве РФ (125993, Россия, г. Москва, Ленинградский пр-кт, 49, NAEkimova@fa.ru)

\section{МИРОВЫЕ НАУЧНО-ТЕХНОЛОГИЧЕСКИЕ ТРЕНДЫ И ВЫЗОВЫ РЫНКУ ТРУДА В РОССИИ}

\begin{abstract}
Аннотация. Зарубежные и российские исследования указывают на стремительное изменение глобального научно-технологического ландшафта. Эффект от технологических трансформаций уже проявляется практически во всех сферах жизнедеятельности общества, в т.ч. приводит к радикальной перестройке на рынке труда. В частности, новые технологии способствуют постепенному исчезновению ряда профессий и появлению новых специальностей, связанных с управлением современными технологическими процессами.
\end{abstract}

Ключевые слова: научно-технологические тренды, рынок труда, цифровизация, технологическая политика, занятость

\section{Введение}

Сегодня в мире происходит формирование так называемого постиндустриального общества, для которого характерно развитие таких типов экономики, как циклическая [Mathews, Tan 2016], серебряная [Коломиецс 2018], одноранговая [Андреев 2019], роботомика [Балацкий, Екимова 2021]. Их формирование происходит на фоне стремительно меняющейся технологической картины мира, идеологическим ядром которой часто выступает концепция четвертой промышленной революции. Ядро технологических особенностей Индустрии 4.0 формируют цифровые технологии, а также конвергенция цифровых, физических и биологических систем [Балацкий 2019]. Как результат, происходит массовое вытеснение физического труда вследствие автоматизации и роботизации производственных процессов. Соответственно, успешная адаптация к четвертой промышленной революции на национальном уровне требует постоянного отслеживания зарождающихся и набирающих обороты технологических трендов для своевременной и эффективной реакции на них.

Цель статьи состоит в том, чтобы проанализировать перспективные технологические тренды и оценить потенциальные вызовы государственному регулированию с их стороны.

\section{Мониторинг глобальных}

\section{научно-технологических трендов}

Мониторинг глобальных научно-технологических трендов входит в сферу интересов как государственных органов, ответственных за инновационную политику, так и множества аналитических и исследовательских организаций. Формирование будущего технологического ландшафта для отдельной страны или мира в целом служит отправной точкой для подготовки долгосрочных национальных стратегий не только в рамках научно-технологической сферы. Подавляющее большинство таких мониторингов основывается на экспертных опросах, в особенности форсайт-исследованиях, а также на глубоком изучении публикационного или патентного ландшафта. Если говорить о перспек- 
тивных трендах или вызовах, составленных зарубежными и отечественными разработчиками, то в первую очередь следует обратить внимание на следующие исследования.

В зону ответственности ОЭСР, помимо прочего, входит подготовка аналитических и статистических материалов в области науки, технологий и инноваций. Частью этой работы является формулирование и анализ общих глобальных и технологических трендов. Группа первых включает рост и старение населения, ухудшение экологической обстановки, обострение конфронтации на геополитической арене и т.д. ${ }^{1}$ Перспективные технологические вызовы представлены развитием следующих 10 «подрывных» технологий, которые будут иметь наибольший резонанс в различных сферах общественной жизни: это аддитивное производство, продвинутые системы хранения энергии, искусственный интеллект, аналитика больших данных, технологии распределенного реестра, Интернет вещей, микро- и наноспутники, наноматериалы, нейротехнологии, синтетическая биология ${ }^{2}$. При этом выделяются еще 30 технологий, которые также имеют крайне высокий потенциал трансформации глобального мироуклада.

Организация $\operatorname{ESPAS}$ (Европейская система политической стратегии и анализа, European Strategy and Policy Analysis System), которая объединяет сеть исследовательских центров из стран ЕС, в 2015 г. выпустила отчет о глобальных мегатрендах, с которыми столкнутся страны Европы до 2030 г. ${ }^{3}$ Среди технологических вызовов были выделены трансформация общества под воздействием нового промышленного производства, биотехнологий и цифровизации и усиление роли автономности в процессе принятия решений (искусственный интеллект). К числу наиболее важных технологических новшеств были отнесены Интернет вещей, большие данные, умное производство, объединение роботов, нанотехнологий и искусственного интеллекта и др.

Институт «Будущее сегодня» (The Future Today Institute) осуществляет ежегодный мониторинг технологических трендов, которые способны в обозримом будущем кардинально изменить экономику и общество. В обзоре 2021 г. было выделено порядка пяти сотен таких трендов в разрезе основных областей их возможного воздействия ${ }^{4}$. Соответственно, эти области выступают в качестве очагов технологической модернизации. В частности, к ним относятся: искусственный интеллект, системы машинного зрения, дополнительная реальность, $5 G$ и роботы, системы распределенного реестра и ФинТех, биотехнологии и др.

Учитывая значимость и масштабность цифровой трансформации общества, ряд аналитических компаний выбрали в качестве своей специализации предсказание технологических трендов исключительно в этой области. Так,

1 An OECD horizon scan of megatrends and technology trends in the context of future research policy. - OECD. 2016. URL: https://ufm.dk/en/publications/2016/an-oecd-horizonscan-of-megatrends-and-technology-trends-in-the-context-of-future-research-policy (accessed 06.07.2021).

2 OECD Science, Technology and Innovation Outlook 2016. - OECD. 2016. P. 79-80. URL: https://www.oecd.org/fr/sti/oecd-science-technology-and-innovation-outlook-25186167.htm (accessed 06.07.2021).

3 Global trends to 2030: can the EU meet the challenges ahead? - European Strategy and Policy Analysis System (ESPAS). 2015. URL: https://espas.secure.europarl.europa.eu/orbis/sites/default/ files/espas_files/about/espas-report-2015.pdf (accessed 06.07.2021).

4 14th Annual Tech Trends Report. - Future Today Institute. 2021. URL: https://futuretodayinstitute.com/trends/ (accessed 06.07.2021). 
аналитики Gartner ${ }^{1}$, Accenture ${ }^{2}$ и IDC ${ }^{3}$ сходятся во мнении, что искусственный интеллект, Интернет вещей, виртуальная реальность и облачные вычисления способны полностью преобразить мировое производство в ближайшие годы. Отмечается, что распространение и массовое внедрение этих технологий еще больше усилит цифровое неравенство и социальную поляризацию как внутри государств, так и между ними.

В России практика построения технологических прогнозов имеет достаточно богатую историю. В последнее время особую популярность приобрели технологические форсайты, организуемые при активном участии НИУ ВШЭ [Гохберг и др. 2017]. Фундаментом для Прогноза научно-технологического развития России на период до 2030 года послужило как раз одно из таких исследований. Организаторами форсайта была сформирована экспертная сеть из свыше 200 учреждений и более 2 тыс. специалистов, которые оценили спектр важнейших технологий и отсортировали их распространение по временной шкале. В состав ключевых технологических областей вошли: ИКТ, биотехнологии, медицина и здравоохранение, новые материалы и нанотехнологии, рациональное природопользование, транспортные и космические системы, энергоэффективность и энергосбережение 4 . Выделенные области послужили и продолжают служить своеобразными маяками для государственной научнотехнической политики России, в т.ч. для распределения бюджетных средств. Аналог форсайта был использован при начертании дорожных карт сквозных технологий, вошедших в национальную программу «Цифровая экономика Российской Федерации». Важно отметить, что в состав национальной программы включен федеральный проект «Кадры для цифровой экономики», предполагающий реализацию комплекса мероприятий по подготовке высококвалифицированных кадров для цифровой экономики.

\section{Трансформация рынка труда}

Эффект от масштабных технологических трансформаций, как показывает история, проявляется практически во всех сферах жизнедеятельности общества. Далеко не в последнюю очередь они приводят к радикальным перестройкам на рынке труда. В частности, новые технологии способствуют отмиранию профессий, которые, например, могут выполняться машинами, и появлению новых специальностей, связанных с управлением новыми технологическими процессами. Очевидно, что одним из залогов успешной адаптации к перспективным научно-технологическим трендам на национальном уровне выступает своевременная перестройка системы подготовки кадров с учетом актуальных и будущих потребностей рынка труда.

Международная организацией труда (МОТ) в целях прогнозирования будущих шоков рынка занятости реализует проект «Будущее работы» (The Future of Work), в рамках которого регулярно публикуются аналитические отчеты. В одном из них отмечается, что технологическая революция не только повлечет

14 Impactful Technologies from the Gartner Emerging Technologies and Trends Impact Radar for 2021. - Gartner. 2021. URL: https://www.gartner.com/smarterwithgartner/4-impactful-technologies-from-the-gartner-emerging-technologies-and-trends-impact-radar-for-2021/ (accessed 06.07.2021).

${ }^{2}$ COVID-19: Post-Coronavirus technology trends. - Accenture. 2020. URL: https://www.accenture.com/us-en/insights/technology/tech-vision-coronavirus-trends (проверено 06.07.2021).

3 FutureScape: Worldwide IT Industry 2021 Predictions. - IDC. 2020. URL: https://www.idc. com/getdoc.jsp?containerId=US46942020 (accessed 06.07.2021).

4 Прогноз научно-технологического развития России: 2030. М.: Министерство образования и науки РФ, НИУ ВШЭ. 2014. 244 с. 
за собой сокращение рабочих мест из-за процессов автоматизации, но и будет генерировать массу новых возможностей для занятости [Nübler 2016]:

- во-первых, сокращение рабочего времени и рост доходов приводит к росту спроса на досуг, что детерминирует создание целых новых отраслей индустрии отдыха и услуг;

- во-вторых, технологические инновации, которые вытесняют работников в отраслях - потребителях технологий, создают спрос на специалистов в отраслях - производителях технологий;

- в-третьих, распространение автоматизации в отраслях, основанных на обслуживании и непосредственном контакте с потребителями, стимулирует разработку новых моделей бизнеса для поддержания отношений с клиентами. Автоматизация задач в сфере услуг снижает затраты, но также сокращает личное взаимодействие с клиентами, которое, как правило, является основным фактором укрепления доверия и привлечения новых клиентов. Поэтому предприятия разрабатывают новые виды услуг, которые создают новые рабочие места и привлекают специалистов, работа которых находится под угрозой;

- в-четвертых, распространение многих инноваций требует строительства и расширения инфраструктуры, в возведении которой задействуется множество работников как низкой, так и высокой квалификации;

Таблица 1

Прогноз изменения спроса на группы профессий к 2030 г.

\begin{tabular}{|l|c|c|c|c|c|c|}
\hline \multicolumn{1}{|c|}{ Группа профессий } & Китай & Германия & Индия & Япония & Мексика & США \\
\hline $\begin{array}{l}\text { Творческие работники } \\
\text { (художники, дизайнеры и др.) }\end{array}$ & $+85 \%$ & $+17 \%$ & $+58 \%$ & $-4 \%$ & $+28 \%$ & $+8 \%$ \\
\hline Компьютерные специалисты & $+50 \%$ & $+59 \%$ & $+129 \%$ & $+15 \%$ & $+27 \%$ & $+34 \%$ \\
\hline Учителя & $+119 \%$ & $+17 \%$ & $+208 \%$ & $-8 \%$ & $+37 \%$ & $+9 \%$ \\
\hline Менеджеры & $+40 \%$ & $+21 \%$ & $+75 \%$ & $0 \%$ & $24 \%$ & $+15 \%$ \\
\hline Строители & $+9 \%$ & $+13 \%$ & $+117 \%$ & $-16 \%$ & $+48 \%$ & $+35 \%$ \\
\hline Работники здравоохранения & $+122 \%$ & $+25 \%$ & $+242 \%$ & $-1 \%$ & $+83 \%$ & $+30 \%$ \\
\hline $\begin{array}{l}\text { Высококвалифицированные } \\
\text { вециалисты ученые, финансо- } \\
\text { вые аналитики, адвокаты) }\end{array}$ & $+26 \%$ & $+20 \%$ & $+46 \%$ & $+2 \%$ & $+32 \%$ & $+11 \%$ \\
\hline Офисные работники & $+14 \%$ & $-15 \%$ & $+21 \%$ & $-23 \%$ & $+22 \%$ & $-20 \%$ \\
\hline $\begin{array}{l}\text { Работники физического труда } \\
\text { впрогнозируемыхусловиях } \\
\text { (уборщики, повара, сотрудники } \\
\text { ремонтных цехов и т.п.) }\end{array}$ & $-4 \%$ & $-21 \%$ & $+15 \%$ & $-33 \%$ & $+8 \%$ & $-31 \%$ \\
\hline Работники сферы обслуживания & $+36 \%$ & $+11 \%$ & $+46 \%$ & $-13 \%$ & $+15 \%$ & $-1 \%$ \\
\hline $\begin{array}{l}\text { Работники физического труда } \\
\text { в непрогнозируемых условиях } \\
\text { (спасатели, установщики } \\
\text { оборудования, сезонные с } \backslash \text { работники) }\end{array}$ & $+12 \%$ & $-6 \%$ & $+9 \%$ & $-5 \%$ & $+16 \%$ & $+6 \%$ \\
\hline
\end{tabular}

Источник: Jobs lost, jobs gained: workforce transitions in a time of automation. - McKinsey Global Institute. 2017. URL: https://www.mckinsey.com/featured-insights/future-of-work/ jobs-lost-jobs-gained-what-the-future-of-work-will-mean-for-jobs-skills-and-wages\# (accessed 14.09.2021). 
- в-пятых, распространение инновационной и технологической культуры в обществе создает плодородную почву для появления креативных предпринимателей, которые проектируют и разрабатывают принципиально новые товары и услуги, разрабатывают новые бизнес-модели и создают новые рабочие места.

Компания McKinsey реализовала проект по оценке изменения спроса на разные специальности к 2030 г. в крупнейших мировых экономиках 1 . Ключевым фактором будущей деформации рынка труда является автоматизация производственных процессов, что обусловит рост спроса на высококвалифицированные трудовые ресурсы и, наоборот, спровоцирует его снижение на персонал среднего уровня квалификации (см. табл. 1). Кроме того, важную роль сыграют старение населения, рост доходов и объема потребления в развивающихся странах, расширение «зеленой» экономики и др.

В 2017 г. был опубликовано исследование консалтинговой компании The Boston Consulting Group «Россия 2025: от кадров к талантам», в котором по данным опроса широкой и репрезентативной выборки отечественных предприятий были сформированы сценарии изменения рынка труда в России к 2025 г. $^{2}$ Среди факторов, оказывающих негативное влияние на технологическую трансформацию экономики страны, были выделены: отсутствие критической массы спроса на знания или низкий уровень привлекательности для талантов; неприспособленность системы высшего образования к требованиям и запросам экономики знаний; низкое качество среды для развития и самореализации талантов. Эти обстоятельства могут стать непреодолимым препятствием для поддержания конкурентоспособности России и в т.ч. привести к еще большему истощению человеческого капитала. Что касается видения глобального рынка труда, то авторы исследования спрогнозировали исчезновение от 9\% до 50\% всех ныне существующих профессий вследствие цифровизации, а $19 \%$ всех рабочих мест могут быть замешены роботами на $81 \%$. Для структурного анализа российского рынка труда был применен подход Й. Расмуссена, предполагающий выделение трех ключевых категорий задач для всех видов занятости: «умение», «правило» и «знание» (см. рис. 1).

Согласно базовому (догоняющему) сценарию трансформации рынка труда в России, к 2025 г. 8,6 млн граждан потеряют свою работу из-за невостребованности их специальностей, а в категории «знание» сформируется дефицит в 5,8 млн специалистов. По сценарию опережающей модернизации работы лишатся около 10 млн чел., представляющих категории «умение» и «правило», а в когорте «знание» возникнет 9,2 млн новых рабочих мест - примерно поровну в частном секторе и компаниях с государственным участием.

Помимо макроэкономического взгляда на будущее рынка труда, в России существуют различные прогнозы появления и исчезновения отдельных специальностей в кратко- и среднесрочной перспективе. Наиболее известным из таких исследований является «Атлас новых профессий», впервые опубликованный в 2014 г. под эгидой Агентства стратегических инициатив и Московской школы управления СКОЛКОВО 3 . В основу Атласа легла серия форсайт-сессий с представителями бизнеса, органов власти и научно-образовательного

1 Jobs lost, jobs gained: workforce transitions in a time of automation. - McKinsey Global Institute. 2017. URL: https://www.mckinsey.com/featured-insights/future-of-work/jobs-lost-jobsgained-what-the-future-of-work-will-mean-for-jobs-skills-and-wages\# (accessed 14.09.2021).

2 Россия 2025: от кадров к талантам. - BCG. 2017. Доступ: https://image-src.bcg.com/ Images/Russia-2025-report-RUS_tcm9-188275.pdf (проверено 14.09.2021).

3 Атлас новых профессий. - Агентство стратегических инициатив (АСИ). 2014. Доступ: https://career.urfu.ru/fileadmin/user_upload/site_15748/files/Atlas_novykh_professii.pdf (проверено 14.09.2021). 


\begin{tabular}{|c|c|c|c|c|}
\hline & & Характерработы & Требуемые знания & Примеры профессий \\
\hline & Умение & $\begin{array}{l}\text { Более } 50 \% \text { задач - это: } \\
\text { Повторяющиеся типовые } \\
\text { задачи } \\
\text { Физический труд }\end{array}$ & $\begin{array}{l}\text { Не требует подготовки или } \\
\text { достаточно короткого } \\
\text { обучения }\end{array}$ & $\begin{array}{l}\text { (1) Подсобные рабочие, уборщики } \\
\text { (2) Водители, продавцы }\end{array}$ \\
\hline & Правило & $\begin{array}{l}\text { Более } 50 \% \text { задач - это: } \\
\text { Техническая, рутинная работа } \\
\text { Принятие решений в рамках } \\
\text { предписанных правил и } \\
\text { инструкций }\end{array}$ & $\begin{array}{l}\text { Не требует подготовки или } \\
\text { достаточно короткого } \\
\text { обучения }\end{array}$ & $\begin{array}{l}\text { (3) Квалиф. работники сферы услуг, с/х } \\
(4 \text { Операторы пром. установок } \\
\text { (5) Квалифицированные рабочие } \\
\text { (6) Специалисты среднего уровня } \\
\text { (7) Государственные служащие }\end{array}$ \\
\hline$\theta B$ & Знание & $\begin{array}{l}\text { Более 50\% задач - это: } \\
\text { Аналитическая работа } \\
\text { Импровизация } \\
\text { Работа с неопределенностью } \\
\text { Автономность принятия } \\
\text { решений }\end{array}$ & $\begin{array}{l}\text { Высокий уровень } \\
\text { образования } \\
\text { Широкий кругозор }\end{array}$ & $\begin{array}{l}8 \text { Преподаватели } \\
9 \text { Экономисты, юристы } \\
\text { Прочие специалисты высшего уровня } \\
\text { (1) квалификации, преподаватели в вузах } \\
\text { (11) Врачи высокой квалификации } \\
\text { (12) Руководители } \\
\text { (13) Физики, химики, инженеры } \\
\text { (14) Научные работники }\end{array}$ \\
\hline
\end{tabular}

Источник: Россия 2025: от кадров к талантам. - BCG. 2017. Доступ: https://image-src.bcg. com/Images/Russia-2025-report-RUS_tcm9-188275.pdf (проверено 14.09.2021).

\section{Рисунок 1. Иллюстрация подхода Й. Расмуссена с примерами профессий}

сообщества, результаты которых воплотились в перечень более чем из 100 перспективных профессий в 19 отраслях. Кроме того, был составлен список профессий, которые устареют до и после 2020 г. Например, среди интеллектуальных специальностей в разряд бесперспективных попали: турагент, лектор, нотариус и журналист, а среди рабочих - почтальон, шахтер и инспектор дорожно-патрульной службы. В 2020 г. вышло 3-е издание Атласа 1 , в котором круг рассматриваемых отраслей расширился до 27 наименований, соответственно увеличив перечень перспективных профессий. В частности, востребованными профессиями будущего в финансовом секторе будут: разработчик персональных пенсионных планов, оценщик интеллектуальной собственности, аудитор по зеленому финансированию, мультивалютный переводчик, менеджер фонда прямых инвестиций в талантливых людей, проектировщик индивидуальной финансовой траектории и др. К ключевым трендам, меняющим занятость в стране, были отнесены цифровизация, автоматизация, глобализация, рост требований к экологичности, развитие сетевой организации общества, рост скорости изменений и рост сложности управления. К новым наиболее значимым технологическим секторам были причислены медицина, робототехника, биотехнологии и нейротехнологии.

В рамках проекта НИУ ВШЭ «Мониторинг глобальных технологических трендов» были составлены «Атлас технологий будущего» [Соколова и др. 2017] и «Атлас профессий будущего» [Гохберг и др. 2019]. Помимо форсайт-исследования, разработчики этих атласов опирались на анализ количественных параметров российского и мирового рынков труда, больших данных, семантический анализ научных публикаций и др. В разряд наиболее перспективных технологических трендов попали: развитие искусственного интеллекта, новая индустриальная революция; роботизация и Интернет вещей; облачные

1 Атлас новых профессий 3.0 (под ред. Д. Варламовой, Д. Судакова). 2020. М.: Интеллектуальная Литература. 456 с. 
технологии и всепроникающие социальные медиа; синтетическая биология; технологии создания новых материалов (в т.ч. наноструктурированных) и др. Влияние этих технологий уже проявляется и будет проявляться в виде замены рутинного труда искусственным интеллектом, повышения роли креативных услуг, структурной безработицы из-за растущих требований к технологическим и социальным навыкам, роста сегмента удаленной занятости и трудовой мобильности и т.д. Перспективными профессиями в ближайшем будущем, по мнению авторов исследования, должны стать: исследователь данных, датажурналист, дизайнер образовательной программы, юрист в сфере информационных технологий, менеджер индивидуальных медицинских программ и т.п.

\section{Заключение: вызовы государственному регулированию}

Очевидно, что и сами мировые научно-технологические тренды, и вызываемая ими трансформация рынка труда в России требуют своевременной и эффективной реакции от национальных властей. Во-первых, государство является крупнейшим заказчиком в системе подготовки кадров и способно принять меры для обеспечения экономики необходимы специалистами. Во-вторых, новые технологии и новые профессии требуют соответствующего нормативно-правового регулирования. В-третьих, подчинение общей стратегии развития России требованиям глобальной производственной и сервисной модернизации видится витальным фактором поддержания национальной конкурентоспособности.

\footnotetext{
Статья подготовлена в рамках государственного задания Правительства РФ Финансовому университету на 2021 г. по теме «Направления модернизации российской университетской системы с учетом запросов реального сектора экономики и мировых технологических трендов».
}

\section{Список литературы}

Андреев К. 2019. Одноранговая экономика. Екатеринбург: Издательские решения. $106 \mathrm{c.}$

Балацкий Е.В. 2019. Глобальные вызовы четвертой промышленной революции. - Terra Economicus. Т. 17. №. 2. С. 6-22.

Балацкий Е.В., Екимова Н.А. 2021. Инструменты государственного управления: прогнозирование vs проектирование. - Управленеи. Т. 12. № 1. С. 18-31.

Гохберг Л.М. и др. 2019. Атлас профессий будущего. М.: ИД ВШЭ. 148 с.

Гохберг Л.М., Соколов А.В., Чулок А.А. и др. 2017. Глобальные тренды и перспективы научно-технического развития Российской Федерации: краткие тезисы. М.: ИД ВШЭ. 39 с.

Коломиецс П.Н. 2018. «Серебряная экономика» - новый подход к проблеме старения. - Journal of Economic Regulation. Т. 9. № 1. С. 89-101.

Соколова А.В. и др. 2017. Атлас технологий будущего. М.: Точка. 192 с.

Mathews J.A., Tan H. 2016. Circular Economy: Lessons from China. - Nature. Vol. 531. P. 440-442.

Nübler I. 2016. New Technologies: A Jobless Future or Golden Age of Job Creation. - International Labour Office Research Department. Working Paper No. 13. P. 22-23. 
YUREVICH Maxim Andreevich, Researcher at the Center for Macroeconomic Research, Financial University under the Government of the Russian Federation (49 Leningradsky Ave, Moscow, Russia, 125993; mayurevich@fa.ru)

EKIMOVA Natalya Aleksandrovna, Cand.Sci. (Econ.), Associate Professor; Leading Researcher at the Center for Macroeconomic Research, Financial University under the Government of the Russian Federation (49 Leningradsky Ave, Moscow, Russia, 125993; n.ekimova@bk.ru)

\title{
GLOBAL S\&T TRENDS AND CHALLENGES TO THE LABOR MARKET IN RUSSIA
}

\begin{abstract}
Foreign and Russian studies demonstrate a rapid change in the global scientific and technological landscape. Based on the review of analytical studies, the most important technological innovations are Internet of Things, big data, smart manufacturing, combining robots, nanotechnology and artificial intelligence, etc. The effect of technological transformations is already manifesting itself in almost all spheres of society, including leading to radical restructuring in the labor market. In particular, new technologies contribute to the withering away of professions that performed by machines, and the emergence of new professions associated with the management of new technological processes. It is obvious that one of the keys to successful adaptation to promising scientific and technological trends at the national level is the timely restructuring of the personnel training system, taking into account the current and future needs of the labor market.

Consequently, the world scientific and technological trends themselves, and the transformation of the labor market in Russia caused by them, require a timely and effective response from the national authorities. First, the state is the largest customer in the personnel training system and is able to take measures to provide the economy with the necessary specialists. Second, new technologies and new professions require appropriate regulations. Third, the subordination of the general development strategy of Russia to the requirements of global production and service modernization is seen as a vital factor in maintaining national competitiveness.
\end{abstract}

Keywords: S\&T trends, labor market, digitalization, STI policy, employment 